\title{
Search and Price Dispersion in Online Grocery Markets
}

\author{
Timothy J. Richards, Stephen F. Hamilton, and William Allender* \\ May 9, 2016
}

\begin{abstract}
Consumers often purchase multiple products at a time from retailers, creating multi-product incentives for search. In this paper we consider how product variety affects consumer search intensity and the dispersion of prices in multi-product retail markets. We employ online grocery pricing data from four large retailers in the UK to estimate search costs and equilibrium price dispersion for food products under circumstances where: (i) consumers search for single products; and (ii) consumers search for multiple products at once. We compare estimates in each case between a model in which utility increases with product variety and a model in which utility is not a function of variety. Relative to our preferred specification with variety effects in utility, we find estimates of both search cost and search frequency to be biased upwards in single product settings when variety effects are ignored; however, we find estimates of search costs are biased upwards while search frequency is biased downwards in multi-product settings when variety effects in utility are ignored.
\end{abstract}

keywords: consumer search, online retailing, price dispersion, variety.

${ }^{*}$ Richards is Professor and Morrison Chair of Agribusiness, Morrison School of Agribusiness, W. P. Carey School of Business, Arizona State University, Mesa, AZ, 85212. Ph. 480-727-1488, email: trichards@asu.edu. Hamilton is Professor in the Department of Economics, Orfalea School of Business, California Polytechnic State University San Luis Obispo, San Luis Obispo, CA. email: shamilto@calpoly.edu. Allender is Assistant Professor of Marketing, DeGroot School of Business, McMaster University, Hamilton, ON. email: allendw@mcmaster.ca. Copyright 2014. Users may copy with permission. The authors gratefully acknowlege funding from the Agriculture and Food Research Initiative of the National Institute for Food and Agriculture, USDA. 


\section{Introduction}

Consumers often purchase more than one product at a time from retailers. For example, grocery products are generally purchased from supermarkets in shopping baskets containing multi-category, multiproduct goods. In multiproduct retail environments, consumers typically face a wide assortment of products from which to choose and make multiple choices within a short duration of time. Wider product assortments offered by retailers can complicate the search process by providing consumers with more potential choices to sift through, but product variety can also facilitate the search process by making it easier for consumers to find products that provide suitable matches with their tastes. In this paper we examine how consumer search costs vary with product variety in multiproduct environments.

Our observations on how search costs vary with the number of products are derived from data on consumer's online grocery purchases. Online retailing has particularly important implications for consumer search, because the online environment differs from traditional retailing both in terms of reduced cost of consumer search and decreased stocking cost of providing greater product variety. Moreover, the magnitude of search frictions in online markets has essential implications for food retailing in light of the small margins earned by existing retailers and the expected growth in online food retailing, which is expected to grow much more rapidly than traditional grocery sales over the next decade at a rate of more than $10 \%$ per year. ${ }^{1}$ Moreover, Amazon and Walmart are now beginning to compete in the "order and deliver" market, removing many of the obstacles to growth (access, delivery, and price) of the online grocery segment. ${ }^{2}$

For individual products, it is well documented that the law of one price is often violated in practice (Means 1939). Price dispersion for seemingly identical products can emerge at a given point in time due to coexistence of informed and uninformed consumers (Varian 1980;

\footnotetext{
${ }^{1}$ Traditional retail outlets account for roughly $\$ 500.0$ billion in sales, and non-conventional outlets, such as club stores, discounters and drugstores, the remaining \$500.0 million (Hartman 2012).

${ }^{2}$ The online grocery market consists of "order and deliver," "order online and store pick-up," "specialty online," and "online order and shipment" sub-segments (Hartman 2012).
} 
Burdett and Judd 1983; Carlson and McAfee 1983), to mixed populations of consumers with high and low valuations (Jeuland and Narasimhan 1985; Pesendorfer 2002), to differences among consumers in store loyalty (Villas-Boas 1995), and to variation in consumer search intensity (Wilde and Schwartz 1979). In cases where price dispersion is driven by a lack of consumer information, one would expect that defections from the law of one price would be tempered in the online retail environment, as online retailing puts rivals' prices at consumers fingertips, facilitating price comparison. Yet, surprisingly, Brynjolfsson and Smith (2000), Clay, Krishnan, and Wolff (2001), and Goolsbee (2001) document significant price variation in online markets, even for products such as book titles that are virtually identical across online retailers. This evidence, like much of the empirical evidence on online search behavior, is derived from markets in which consumers search for single products. Here, we extend the analysis of price variation in online markets to settings in which consumers search among and purchase multiple products at a time.

Our paper contributes to a fundamental, unresolved debate regarding how search costs are impacted by product variety. Because product variety is a key strategic variable among retailers in multiproduct environments (Briesch, Chintagunta, and Fox 2009; Richards and Hamilton 2014), the nexus between product variety and search costs provides retailers with a potential opportunity to exert market power. Namely, to the extent that search costs involve a unique process of examination and consideration for each product, then search costs rise in the number of products available; however, if certain elements of search involve fixed costs that can be shared across multiple products, for instance the cost of driving to a store and finding a parking spot, then search costs decrease on average with the number of products considered. ${ }^{3}$ Moreover, if greater product variety implies that products are more

\footnotetext{
${ }^{3}$ This debate is also related to the question of how choice behavior changes with variations in assortment. While McAlister and Pessemier (1982) argue that utility always rises in variety as each consumer has a higher probability of finding a product that matches his or her preferences, Diehl and Poyner (2010) find evidence to the contrary, namely that the probability of any choice at all falls as the number of choices rises. Some argue that such studies provide evidence of a "disutility of choice" while others maintain that the experiments used in these papers merely capture the effect of higher search and processing costs on the probability of choice.
} 
densely packed into a given attribute space, then introducing finer differentiation among products makes it easier for consumers to find suitable matches with their tastes, reducing the marginal return to continued search (Richards, Hamilton and Empen 2015). Our online data on consumer grocery purchases, which captures variation in variety and prices in several product categories, allows us to exploit inter-category variation in the number of products available to examine the bias inherent in search cost estimates when variety is not taken into account.

We frame our model along the lines of recent research that identifies search costs using price-only data. Following the model of equilibrium price dispersion derived by Burdett and Judd (1983), Hong and Shum (2006) estimate search costs using an empirical approach based on the mixed-strategy price equilibrium. Imposing the equilibrium conditions implied by both sequential and non-sequential search on the resulting price distribution, they are able to solve for the indifference points in the distribution of search costs using an empirical likelihood approach. ${ }^{4}$ Moraga-Gonzalez and Wildenbeest (2008) estimate a similar model using more traditional maximum likelihood estimation, and Wildenbeest (2011) extends this approach to a differentiated-product environment in which firms compete directly in utility space in the sense of Armstrong and Vickers (2001). Wildenbeest (2011) focuses on single-product purchases (baskets of groceries), and we depart from this approach by basing our model on the multiproduct mixed-strategy price equilibrium derived by McAfee (1995). Doing so allows us to incorporate price interactions between individual items in a multiproduct shopping basket, revealing the extent of the bias in search cost estimates when consumer preferences for product variety are ignored in markets with multi-product interactions. ${ }^{5}$

Our findings contribute to the literature on search and equilibrium price distributions in

\footnotetext{
${ }^{4}$ Although Hong and Shum (2006) estimate search costs for both sequential and non-sequential search, de Los Santos, Hortacsu and Wildenbeest (2012) reject the sequential search model, so we focus our attention on the non-sequential, or fixed sample size, alternative.

${ }^{5}$ Use of the multiproduct mixed-strategy price equilibrium model of McAfee (1995) is appropriate under circumstances in which consumers do not necessarily buy multiple products from the same store, but nevertheless are able to receive information from multiple vendors of similar products.
} 
a number of ways. First, we estimate search costs in a multiproduct environment in which search occurs not only between multiple options within one category, but also within multiple categories on a single shopping trip. This environment is both realistic and revealing, as it presents a significantly more complex decision space for individual consumers. Second, we extend the existing econometric methods of identifying price distributions for single products into a multiproduct framework. While Hong and Shum (2006), Moraga-Gonzalez and Wildenbeest (2008), and Wildenbeest (2011) develop maximum likelihood methods of estimating search costs for single products, the multiproduct problem is at once both more descriptive of actual shopping behavior, and inherently more complex. Third, we examine the effect of product differentiation on equilibrium price distributions, and search costs. Much of the previous work in this area uses data on homogeneous products in order to control for all sources of price variation other than variation in search intensity, whereas we extend the differentiated-products approach of Wildenbeest (2011) to account for product differentiation for individual brands within individual stores, at a level where consumer choices are routinely made. Adding product differentiation to our model of consumer search allows us to examine the implications of search in a truly differentiated, multiproduct retail environment.

In the next section, we provide some background on existent models of multiproduct search. In the third section, we describe our online grocery data, and highlight some observations that point to the salience of our research question, namely that online prices tend to be highly disperse. In the fourth section, we develop an equilibrium model of price dispersion in which costly consumer search plays a prominent role, and emphasize the importance of multiproduct search in an online-retailing context. In this section, we also show how we incorporate the effect of variety on empirical search costs, both in single-product and multiproduct search environments. We present and interpret our estimation results in the fifth section, while the sixth concludes and offers more general implications for other forms of online retailing. 


\section{Background on Multiproduct Search}

Models of online price dispersion typically consider search for a single product, for instance books or electronics. Although search costs in a multiproduct environment are likely to differ fundamentally from those incurred when only one product is searched, the literature remains unsettled on what this means for equilibrium retail prices. Indeed, correlation among prices is one of the key points of contention in the multiproduct search literature. Rhodes (2015) argues that non-advertised and advertised (shopped and non-shopped) prices will be positively correlated because retailers use advertised prices to attract customers to the store, and then must lower prices on the remaining goods because the arriving consumers are inherently price-sensitive; however, Hess and Gerstner (1987) and Lal and Matutes (1994) argue that prices in a model of multiproduct search should be negatively correlated, while McAfee (1995) and Hosken and Reiffen (2007) do not rely on price-transparency at all. ${ }^{6}$

In models of multiproduct search, heterogeneity in valuation (rather than information on product prices) drives the mixed strategy equilibrium. In equilibrium, firms manage the tension between charging higher prices to consumers who do not shop, and setting lower prices to attract those who do. Zhou (2012) considers a sequential model of search in which consumers incur a single search cost to learn the prices and attributes of several products at once. Search is sequential, products are horizontally differentiated by firm, each firm offers all products, and consumers search not only for price, but for attribute matches as well. The analysis reveals a different dynamic that separates single-product from multiproduct search, namely, because there are economies of scope in search, retailers can sell more items to a searching consumer by reducing the price of other products. As in Rhodes (2015), products are priced like complements even though no prior assumptions are made regarding product substitutability, or complementarity. Among the predictions of his model, retail prices can actually fall with higher search costs, because higher search costs strengthen the economies-

\footnotetext{
${ }^{6}$ We consider only equilibrium pricing models, although others consider multiproduct search purely from a consumer perspective (Burdett and Malueg 1981; Carlson and McAfee 1984; Anglin and Baye 1987; Anglin 1990).
} 
of-scope involved in searching, which in turn strengthens the complementarity effect among goods that can be purchased together.

Based on the existing theoretical research, the relationship between search costs in a single-product and multiproduct world remains largely an empirical question. In this paper, we seek to resolve that question by applying a simple, tractable model of search costs using price-only data. While Wildenbeest assumes consumers search for "shopping baskets" based on average prices, average valuations, and average utilities, retailing is inherently a multiproduct service (Rhodes 2015), which makes it natural to consider a multiproduct search process. McAfee (1995) extends the mixed strategy equilibrium of Varian (1980) and Burdett and Judd (1993) in order to account for the fact that products sold at retail are often searched, and purchased, many at a time. In this case, it is not only the draw from one utility distribution that is important, but a single draw from a multivariate utility distribution. We show how the equilibrium utility distribution method of Wildenbeest (2011) can be extended to account for the bias inherent in search cost estimates when variety effects are ignored in a multiproduct retail environment.

\section{Data Sources and Summary Observations}

Our data are from Profitero.com. Profitero is a data-aggregation company that specializes in "scraping" retail pricing data from websites maintained by online retailers. Although Profitero gathers data from a wide variety of online retailers - retailers that sell goods from books to clothing and electronics - our focus is on retailers selling food online. Among global online food markets, the UK is arguably the most mature as all of the major retail players have a substantial online presence. Accordingly, our data describes online grocery prices in the UK. ${ }^{7}$ Tesco, Asda, Sainsbury's and Waitrose each offer online grocery purchasing and delivery service, while currently only Safeway offers on a nation-wide basis in the US. Fully

\footnotetext{
${ }^{7}$ Although our data analysis concentrates on the UK grocery market, current trends in online grocery sales in the UK suggest that insights gained in examining this more mature market may portend similar developments in the US.
} 
$6 \%$ of grocery purchases are online in the UK, compared to less than $0.5 \%$ in the US in 2012 (Butler 2014). If price dispersion is indeed a competitive phenomenon, then the UK online food market represents an opportunity to test our hypotheses regarding the source and nature of retail price variation in online markets. ${ }^{8}$

By comparing prices for the same product across stores in an online environment, we describe retail price distributions for food products, in the absence of traditional search frictions, in a non-parametric way. Estimating equilibrium price distributions using conventional scanner data for brick-and-mortar stores is problematic for a number of reasons. First, online shopping data are used frequently in the search literature because search costs estimated from brick-and-mortar shopping behavior include many elements that are not part of the "pure cognition cost" of finding, studying, considering and evaluating the prices and attributes for alternative products. Other than these pure costs, online shopping is nearly costless. Second, unlike conventional scanner data, the Profitero data does not suffer from aggregation bias. In most retail chains, local managers have substantial latitude to meet competitors' prices, which means that chain-wide price reports, even for one regional market, do not necessarily describe a single pricing strategy. Third, and perhaps most importantly, online food purchases represent a growing share of the grocery trade and look to become a significant part of the food distribution channel in the future. Moreover, developing an understanding of consumer search in online markets provides insight into brick-and-mortar retail behavior by revealing changes in the structure and performance of food markets following a decline in consumer search costs. Indeed, it is possible to price-check products from within a brick-and-mortar retail store using a cell phone.

Consistent with our objective to examine the cost of searching among differentiated products, we focus our attention on the top brands from a small set of focal categories. ${ }^{9}$ Specifi-

\footnotetext{
${ }^{8}$ While Wildenbeest (2011) also uses price data from UK supermarkets, our data is fundamentally different as it describes multiple, individual items instead of shopping baskets, is taken from online shopping sites instead of bricks-and-mortar stores, and includes a much longer sample period (66 weeks versus 12 weeks).

${ }^{9}$ Smith and Thomassen (2012) report that the typical U.K. bricks-and-mortar basket consisted of "...31 products (or 20 categories)..." (p. 311) in 2004, and online baskets are typically substantially larger than their offline equivalents (Degeratu, Rangaswamy, and Wu 2000), so assembling a truly representative basket
} 
cally, our data consists of weekly price observations from 5 frequently-purchased categories: Breakfast cereal, yogurt, carbonated soft drinks, coffee, and jam. Each of these categories are in the top 20 volume categories for all UK grocery sales, and are well-represented by brands that are likely to appear in all stores. In order to compare like products across stores, we choose 10 items from each category (6 in the jam category) that are recognized as the most popular brands by Marketing Magazine, and that are sold in each retailer for all 66 weeks (January 1, 2013 - March 31, 2014) of the data period. ${ }^{10}$ Table 1 shows the list of items in each category, which are matched across retailers by European Article Number (EAN) identifiers. ${ }^{11}$ In table 1 , the binding nature of the constraint that EANs match across retailers is notable. In fact, many of the most common brands described by Marketing Magazine are sold in different packages across retailers. The fact that these common brands are sold by some of the largest food manufactures in Europe points to both the capital required to produce retailer-specific packages, and perhaps also to the level of sophistication involved in recognizing the apparent benefits of obscuring search across retailers.

[table 1 in here]

In assembling this set of brands in each category, we do not intend to describe a typical UK shopping basket as in Wildenbeest (2011). Rather, identifying search costs requires that we compare identical items across stores, and estimate the cost of searching among these brands. Of course, if we are to explain price dispersion among like brands as a function of search costs, it is first necessary to establish that price dispersion does, in fact, exist in our data.

For this purpose, we calculate the mean and standard deviation of price and variety (measured as the number of stock-keeping-units (SKUs)), by category and retailer, and

for empirical purposes would amount to an intractable data problem. However, identifying the relationship between variety and search costs in a multiproduct, online environment does not require that our sample of categories be truly representative.

${ }^{10}$ Although we use time-series data to identify the effect of variation in variety on equilibrium prices, we estimate a static pricing model.

${ }^{11}$ By matching EANs in this way, we implicitly assume that price variation among retailers in our sample set of items is representative of inter-retailer price variation of the entire category. 
show the results in table 2 . This table reveals a number of observations that are important to our subsequent empirical analysis. First, there is substantial variation in both prices and number of items offered across retailers. In the empirical analysis below, we establish that the extent of price variation is indeed statistically significant at the brand level.

[table 2 in here]

Second, there does not appear to be an obvious relationship between variety and categoryaverage price. The fact that no distinct pattern emerges is perhaps to be expected as we identify two possible effects, each counteracting the other, and flowing indirectly through search costs to the retail price. Although Asda offers the lowest category-average price in each case, there is no clear low-price option among the other three retailers. Given that Asda also offers the lowest level of product variety in two of the five categories, low category average prices at Asda provide limited evidence of a trade-off between prices and variety. Similarly, Sainsbury's appears to be a high-variety, high-price option; however, such a correspondence between prices and variety deos not occur for Tesco and Waitrose.

Third, because we include identical products in each category, the size of the price differences among online retailers suggests that there are clear incentives to search. For example, in the cereal category alone, the difference in price between the highest (Waitrose) and lowest (Asda) category-average price is fully 9\%. If shoppers are inclined to search online for price alone, this price difference is likely enough to induce additional search. In summary, it appears as though our sample is sufficient to capture price dispersion in online multiproduct markets, and to estimate implied cost of searching among multiple differentiated products.

\section{Empirical Model of Search Costs with Price Data}

In this section, we describe our empirical approach to estimating how search cost estimates differ when variety is and is not taken into account, and how retailers endogenize assortments to influence consumers' search behavior. Because we estimate this stage of the model using only price data, it is not possible to examine the effect of horizontal differentiation among 
products or retailers; however, we follow Wildenbeest (2011) in demonstrating how vertical differentiation can be incorporated by assuming retailers compete directly in utility and not in prices (Armstrong and Vickers 2001). Competition in utility is both valuable from an empirical perspective, and intuitive as retailers attract customers not only through low prices, but by offering superior service, keeping their stores clean, locating in convenient places, and stocking high-quality fresh foods.

We begin our analysis by considering a setting in which consumers search for items from individual categories - a "stock up" trip for cereal, soft drinks, or yogurt, for example in order to show how including variety can change the conclusions derived from a version of the equilibrium price-dispersion model that is by now well-accepted in the literature. ${ }^{12}$ Moreover, beginning with a single-product approach also highlights the difference between the most general form of our model, the single-item search models that are more common in the literature (Hong and Shum 2006) and the shopping-basket model of Wildenbeest (2011). After estimating search costs in the context of single-product shopping, we then extend the Armstrong-Vickers-Wildenbeest approach to a multiproduct environment as in McAfee (1995) to demonstrate how search behavior in a retail environment with multiple products differs in a fundamental way from this benchmark.

Variety plays a central role in consumers' search process that is not reflected in existing empirical models. For instance, in the extreme case of one retailer offering only one item in a category, search would not occur. Likewise, if a consumer was guaranteed a perfect attribute match for her ideal preferences at any one of a large number of retailers, search would again be unnecessary. Between these extremes, however, search occurs simply because retailers offer assortments in order to match heterogeneous preferences in an imperfect way. We model this process by assuming the cost of search is driven by variation in variety, over time, retailer, and category.

We study this problem using price-only data for a number of reasons. First, price data

\footnotetext{
${ }^{12}$ While such stock up trips are less common than primary shopping trips, Smith and Thomassen (2012) show that secondary trips by shoppers in the UK account for $18 \%$ of all store visits.
} 
are often the only data available for a particular cross section of products, retailers, or markets. In our case, there is no comprehensive data source for online price and volume data for food that covers the entire market. Profitero offers market-level data, but only prices. Second, there is a rich history of theoretical literature that examines price distributions as a means of explaining why the law of one price does not hold. Stigler (1961), Varian (1980), Burdett and Judd (1983), Stahl (1989) and many others derive models of seller behavior that make strong predictions about how equilibrium price distributions behave, which demand empirical testing. Third, empirical researchers are able to extract remarkable insights from looking at price distributions only - insights sufficient to examine our core problem of how retail variety is related to search costs in online markets.

\subsection{Search Costs in a Single-Product Environment}

Using the price-only data provided by Profitero, we estimate a model of price dispersion among the four major online grocery vendors in the UK market. Because the items purchased are identical, we assume any price differences observed online reflect either vertical differentiation created by unobserved differences in customer service, delivery, payment or other aspect of perceived service quality, observed variation in retail variety, or costly consumer search. By controlling for vertical quality differences and assortment depth, we identify variation in search costs implied by the observed price differences, and are able to estimate how search costs vary with assortment depth. We extend our single-product analog to Wildenbeest (2011) to multiproduct price distributions in the next section.

Our estimation strategy extends Moraga-Gonzalez and Wildenbeest (2008) and Wildenbeest (2011) by incorporating variations in retail variety. Search costs can either rise in variety (Diehl and Poynor 2010), or fall (McAlister and Pessemier 1982). We assume consumers use a non-sequential search strategy in which the number of products to search is determined by comparing the marginal cost of search with the marginal benefits of doing so, but where the cost is mediated by the number of products the consumer has to select his or 
her optimal consideration set from. In this sense, our empirical model is a test of the importance of confusion in brand selection - do retailers offer a wide range of products for the express purpose of making comparison more difficult? Such "strategic obfuscation" (Ellison and Ellison 2009) cannot be tested directly, but can form part of a reasoned explanation as to why retailers may find seemingly excessive variety to be, in fact, optimal.

In this section, we describe the model used by Wildenbeest (2011), and then show how it is modified by the inclusion of variety, and then how it can be generalized to multiple product search in the next section. First, we define the utility available from purchasing from retailer $i=1,2, \ldots, N$ to be the difference between a retailer-specific valuation $\left(w_{i}\right)$ and the price paid for an item sold by the retailer (we omit item indices for clarity): $u_{i}=w_{i}-p_{i}$. Provided consumers share a common valuation of quality, and firms produce quality using a constant-returns-to-scale technology, we write the valuation for a truly homogeneous product (h) as the difference between the retailer-specific valuation and the unit-cost of selling food $\left(c_{i}\right): w_{i}-c_{i}=h$. The retailer's margin is then the difference between the value of a particular product and total utility: $p_{i}-c_{i}=h-u_{i}$. Consumers search non-sequentially, or from a fixed sample of stores (De los Santos, Hortacsu and Wildenbeest 2012), and must pay a cost $\left(s_{i}\right)$ to search for another product at another store. If the consumer searches $j$ stores, therefore, the total cost of search is $j s_{i}$. Search costs are random, drawn from a distribution $F\left(s_{i}\right)$ with density $f\left(s_{i}\right)$.

We seek to determine how variety affects search cost estimates, so we allow the unit search cost to depend on variety. There are (at least) two ways in which variety can influence estimated search costs. First, with more products on the shelf, each product becomes more difficult to find as there are more alternatives to search through. Search costs may rise with variety if this effect dominates. Second, if the attribute space is more densely packed with products, the shopper will find product with his or her desired attribute profile more easily, that is, with less search. Search costs may fall as a result. Because we do not know a priori which effect dominates, the net effect is an empirical question. If the total number 
of products offered by retailer $i$ is $n_{i}$, the distribution of search costs is given by $F\left(s_{i}\left(n_{i}\right)\right)$, with density $f\left(s_{i}\left(n_{i}\right)\right)$. Our objective is to estimate the parameters of this distribution.

Consumers optimize their search behavior in the sense that the marginal expected utility from searching $j$ times should be at least equal to the marginal cost of doing so. Define the net marginal benefit of searching $j$ stores as the difference in the expected maximum utility of searching $j$ stores less the cost of search, or $n b_{i, j}=E\left[\max \left\{u_{i}\right\}\right]-j s_{i}$ so in equilibrium $n b_{i, j}=n b_{i, j+1}$ and the cost of searching $j$ stores is $s_{i, j}=E\left[\max \left\{u_{i+1}\right\}\right]-E\left[\max \left\{u_{i}\right\}\right]$. With this assumption, and the assumption that search costs are randomly distributed, the share of consumers searching $j$ stores is given by:

$$
\phi_{j}=\int_{s_{i, j}}^{s_{i, j-1}} f\left(s_{i}\right) d s_{i}=F\left(s_{i, j-1}\right)-F\left(s_{i, j}\right) .
$$

Following Armstrong and Vickers (2001) and Wildenbeest (2011), we assume firms compete in symmetric, mixed strategies in utility space. ${ }^{13}$ Let the utility distribution be denoted by $G\left(u_{i}\right)$ with density $g\left(u_{i}\right)$. A mixed strategy equilibrium implies that firms choose utility levels randomly anywhere in the support of the distribution of consumer heterogeneity, including one in which the utility is zero. Utility is zero for the set of consumers who search only once. If the utility for these consumers is zero, then the firms' margin is given by $h=p_{i}-c_{i}$, and the equilibrium profit is $\pi(0)=h \phi_{1} / N$, or the average valuation for a truly homogeneous product, multiplied by firm $i$ 's market share. More generally, the expected profit over all consumer segments, or consumers who search $i=1,2, \ldots, N$ times is given by:

$$
\pi_{i}\left(u_{i} ; G(u)\right)=\left(h-u_{i}\right) \sum_{j=1}^{N} \frac{j \phi_{j}}{N} G\left(u_{i}\right)^{j-1},
$$

or the retailer-specific margin multiplied by the share-weighted average demand for each store in the market. The mixed strategy equilibrium condition requires the expected profit from selling to consumers searching $j$ times to equal the no-search profit, or:

\footnotetext{
${ }^{13}$ We tested this assumption by examining whether the change in utility for each item, and each store, from each week to the next is linearly dependent on similar changes in other stores (Chiappori, et al. 2002; Wang 2009). We could not reject the null hypothesis of no linear relationship in $96 \%$ of the estimated cases. These results are available from the authors upon request.
} 


$$
h \phi_{1} / N=\left(h-u_{i}\right) \sum_{j=1}^{N} \frac{j \phi_{j}}{N} G\left(u_{i}\right)^{j-1},
$$

which is the condition we use to solve for the equilibrium distribution of utilities. Following Armstrong and Vickers (2001), firms compete in utility space, so maximizing expected profit with respect to $u_{i}$ gives the first-order-condition:

$$
\frac{\partial \pi_{i}}{\partial u_{i}}=\sum_{j=1}^{N} \frac{j \mu_{j}}{N} G(u)^{j-1}-(h-u) \sum_{j=1}^{N} \frac{j(j-1) \phi_{j}}{N} G(u)^{j-2} g(u)=0
$$

where we have imposed symmetry in utilities subsequent to differentiation. Solving this expression for the density of utility, $g(u)$ yields

$$
g(u)=\sum_{j=1}^{N} j \phi_{j} G(u)^{j-1}\left((h-u) \sum_{j=1}^{N} j(j-1) \phi_{j} G(u)^{j-2}\right)^{-1},
$$

which we then estimate using maximum likelihood over all observations for the parameters $\phi_{j}, j=1,2, \ldots, N-1$.

Estimating the model requires values for the utility implied by each store-choice, and item matched across stores. We recover the utilities in (5) by estimating hedonic pricing models with retailer-level fixed effects $\left(\delta_{i}\right)$, item fixed effects $\left(\tau_{k}\right)$, and retailer-specific measures of variety that vary over both retailers and time: $\left(V_{i t}\right): p_{i k t}=\alpha+\delta_{i}+\tau_{k}+V_{i t}+\varepsilon_{i t}$ so that $w_{i k t}=\alpha+\delta_{i}+\tau_{k}+V_{i t}$ and the utility from each retailer simply becomes the negative of the hedonic residuals (Wildenbeest 2011). Variety is measured by the number of unique stock-keeping units (SKUs) in the category of interest for each retailer. Because empirical research shows that consumers prefer variety (Oppewal and Koelemeijer 2005; Richards and Hamilton 2006, 2014; Briesch, Chintagunta, and Fox 2009; Trindade 2010), we argue that equilibrium prices should embody this aspect of vertical differentiation as well. That is, a consumer's valuation reflects her preference for variety in each retailer, so the estimated utilities capture consumers' preference for variety.

Once the distribution of utility is estimated, we then recover equilibrium search costs 
using the relationship captured in (1) subject to the equilibrium condition in (3). Specifically, the optimality of search costs from a consumer's perspective means that they can be written in terms of utility as:

$$
s_{i, j}=\int_{u_{n}}^{u_{m}}(j+1) u G(u)^{j} g(u) d u-\int_{u_{n}}^{u_{m}} j u G(u)^{j-1} g(u) d u,
$$

where $u_{m}$ is the maximum level of utility, and $u_{n}$ is the minimum level. Defining $y=G(u)$ implies $d y=g(u) d u$ so we eliminate the distribution of utility in (6) and write search costs solely in terms of $y$. Further, recognizing that the value of $G(u)$ at the maximum utility level is 1 and at the minimum utility is 0 , we write (6) as:

$$
s_{i, j}=\int_{0}^{1} u(y)\left([(j+1) y-j] y^{j-1} d y,\right.
$$

and the equilibrium level of utility is found by solving (3) for $u$ as:

$$
u=h \sum_{j=2}^{N} j \phi_{j} G(u)^{j-1}\left(\sum_{j=1}^{N} j \phi_{j} G(u)^{j-1}\right)^{-1} .
$$

Numerically integrating (7) subject to the equilibrium condition in (8) provides values for the cost of searching across $j=1,2, \ldots, N$ stores.

With this model, we estimate the share of consumers searching either one, two, three, or all stores in the sample and recover estimates of actual search costs using the distribution function implied by (1) above. We compare estimated search costs with and without the variety effect by first calculating search costs using valuations that include variety, and then removing the variety effect by deducting the product of the hedonic coefficient and the variety level for each observation, and re-calculating the implied search costs. In this way, we are able to formally identify the bias in models that (wrongfully) assume variety does not affect consumer utility. ${ }^{14}$ Thus, our methods allow us to derive inferences on whether observed

\footnotetext{
${ }^{14} \mathrm{~A}$ reviewer suggests that if adding variety to the hedonic regressions always reduces the variance of the residual, then our argument is tautological as the equilibrium cost of searching must fall. However, least squares estimation operates on the square of residuals, while our utility estimates are based on levels.
} 
price dispersion among online retailers is due to search costs or to vertical differentiation among stores, and the extent of the bias in search cost estimates when consumer utility is assumed to be independent of product variety.

Indeed, the estimation routine developed by Moraga-Gonzalez and Wildenbeest (2008) and Wildenbeest (2011) summarized above provides a remarkably simple way to calculate the effect of variety on equilibrium search costs. Through calculating equilibrium search costs implied by utility distributions that do and do not include variety, and comparing the results, we infer the impact of variety on the cost of searching across multiple stores. For example, if the cost of searching a single store is higher for the model that does not include variety relative to the variety-inclusive model, we can conclude that variety reduces search costs, and reduces the incentive for consumers to consider searching across multiple stores. More consumers will search only a single store if they are better able to find products that meet their desired attribute set, and retailers are able to capture a greater share of the market. On the other hand, if variety serves as a means of strategic obfuscation (Ellison and Ellison 2009), greater variety will raise search costs. In equilibrium, consumers will search more stores as the perceived benefit of doing so is correspondingly higher, and each retailer will lose the most desired of shoppers: Those who do not consider more than one store.

\subsection{Search Costs in Multiproduct Retailers}

The model developed to this point is appropriate for estimating search costs when each of $N$ retailers sells a single product. However, as McAfee (1995) explains, the search process in multiproduct retailing is fundamentally different. ${ }^{15}$ If each product has a unique price distribution, then the mixed-strategy equilibrium involves a much more complicated, and

Relative to how our utilities are formed, therefore, our hedonic regressions penalize outliers to a greater extent so it is impossible to say how search costs are affect, a priori, based solely on the mechanics of our algorithm. While they are clearly related, it may be the case that some of the residuals are higher in the non-variety model while others are reduced. Indeed, by construction the mean of the residuals is zero in either case so cannot be imparting any systematic bias through the hedonic regressions.

${ }^{15}$ Indeed, the scenario described by McAfee (1995, p. 84) in which "...consumers can costlessly visit all the stores..." is approximately the case for online grocery purchases so online shopping from multi-product retailers is "...qualitatively different than the single-good problem." 
often unsolvable, problem. In fact, he shows that there are many solutions to the equilibrium price distribution without additional structure. In this section, we describe a simple extension to the single-product approach outlined in the previous section to account for the fact that consumers evaluate many prices simultaneously in deciding the set of products to purchase.

While McAfee (1995) frames the multiproduct problem in terms of the marginal distributions of several products offered by the same retailer, so the formal development of the problem differs little from the single-product case, consumers are instead interested in the probability of drawing a set of prices together for products that they are likely to buy. They draw prices from a multivariate distribution from each retailer, and compare the costs of searching to the prospects of another multivariate draw from another retailer. Therefore, the extension to Wildenbeest (2011), extending the price-distribution logic to the distribution of utilities as we have done so far, is rather simple.

Instead of facing the probability of a single utility from each retailer, the information that is most salient to shoppers is the probability of a particular set of utilities for the products they are interested in. We modify the approach above, therefore, by considering a multivariate distribution over utilities from all five categories, rather than draws from univariate distributions for each item. The difference between our approach and Wildenbeest (2011) is subtle, but important. By considering a single basket of goods, Wildenbeest (2011) ignores the covariance of utilities among goods in the basket. Firms still compete by offering baskets of products, because this is the nature of multiproduct retailing, but when they choose a set of utilities with a particular probability, this probability takes into account the interaction of utilities among products. This extension is both conveniently simple, and powerful as it allows us to compare the implications of multiproduct search, and the impact of variety, directly with our findings from the single-product model.

More formally, the problem from the consumer's perspective now becomes one of comparing the marginal benefit of search to the marginal cost when the probability drawn represents a set of prices, which may or may not co-vary significantly with one another, to the cost of 
finding another set of prices. As in the univariate problem described above, we implicitly assume consumers possess rational expectations in that they are able to determine how many stores to search by comparing the costs and benefits of search on a priori basis. Whereas the sequential-search assumption implies that consumers follow a hierarchical store-thenbrand search process, the non-sequential assumption implies that brands (and their stores) are searched simultaneously, or in a non-hierarchical fashion, and purchase all items from the preferred store. ${ }^{16}$ With this assumption, the share of consumers searching $j$ stores now becomes:

$$
\phi_{j}^{C}=\iint \cdots \int m\left(\mathbf{s}_{i}\right) d \mathbf{s}_{i}=M\left(\mathbf{s}_{i, j-1}\right)-M\left(\mathbf{s}_{i, j}\right),
$$

where $\mathbf{s}$ is now a vector of search costs associated with searching for items chosen from $c=1,2,3, \ldots C$ categories within retailer $i, \phi_{j}^{C}$ is the share searching over the set of $C$ products, and the multiple-integral is over the joint density of search costs $m\left(\mathbf{s}_{i}\right)$.

From the firm's perspective, they now offer a multivariate distribution of prices, and compete in mixed strategies, albeit in a more complicated way, just as they did in the previous problem. Firms compete in utilities according to the Armstrong and Vickers (2001) assumption, so firms now choose the utility from each category, where utilities now represent draws from multivariate distributions $Q\left(\mathbf{u}_{i}\right)$ :

$$
\pi_{i}\left(u_{i} ; Q(\mathbf{u})\right)=\sum_{c=1}^{C}\left(h_{c}-u_{i c}\right) \sum_{j=1}^{N} \frac{j \phi_{j}}{N} Q\left(\mathbf{u}_{i}\right)^{j-1}
$$

which we solve in the same way as (4) above. Namely, the solution results in a system of equations analogous to (5) that we write as:

\footnotetext{
${ }^{16}$ While this is not strictly true, it is approximately true based on data in Smith and Thomassen (2012) who show that retail grocery shoppers in the U.K. spend $80 \%$ of their grocery bill in their top store, and tend to go to only one store for the categories they purchased at that store (94\% of TNS panel survey respondents). Their data, however, describe bricks-and-mortar shoppers, while our data is from online shoppers who, due to fixed shipping costs associated with online groceries, are even less likely to cherry-pick deals online.
} 


$$
q_{c}(\mathbf{u})=\sum_{j=1}^{N} j \phi_{j} Q(\mathbf{u})^{j-1}\left(\left(h_{c}-u_{c}\right) \sum_{j=1}^{N} j(j-1) \phi_{j} Q(\mathbf{u})^{j-2}\right)^{-1}
$$

where $q_{c}(\mathbf{u})$ is the marginal density of utility from category $c$.

So the solution is formally very similar to the univariate case, but allowing for prices to co-vary with one another creates a solution that could be qualitatively different, and our solution is empirically tractable, unlike the theoretical models of McAfee (1995), Rhodes (2015), or Zhou (2012). That is, in the univariate case, the consumer forms expectations of the probability of a high or low utility from a particular retailer that derives from the attributes of, and price of, a single product. In the multivariate case, the consumer similarly forms expectations of the utility being offered, but that utility can be comprised of a highly desirable product offered at a low price, combined with a less desirable product, in another category, offered at a relatively high price, or any combination of price and attributes across multiple products. Any combination of positive or negative correlation among products the key source of contention among recent theoretical studies on this issue (Rhodes 2015, Zhou 2012) - is possible, and can lead to different outcomes relative to the univariate case.

The key insight here is that we can summarize the outcome in our model with one utility draw, and an associated multivariate probability. Empirically, this problem is tractable, and we compare the results directly to the single-product search case. As in the univariate solution above, we also investigate the effect of changing variety simply by allowing utility for each product entering the multivariate problem to depend on the number of products offered by the retailer. If variety in one category at a specific retailer is positively correlated with variety and prices in another category in that retailer, then this will be reflected in the consumer's decision to search another store, or to remain and purchase from the store that changed variety. All we are interested in is the summary outcome, and the net effect on search costs and the probability of searching.

In the multivariate case, we estimate basket-utilities using a multivariate analog to the hedonic approach described above, assuming consumers purchase entire shopping baskets 
at each store. Because there are up to 10 brands in each category, however, there is an intractably large number of potential baskets that can be purchased. ${ }^{17}$ Therefore, in constructing our sample of baskets, we follow the logic of Kamakura and Kwak (2012) and assemble "random baskets" of items for each store on each date. That is, we assume a shopper on each site assembles a basket of consisting of all 5 categories on each visit, where the brands comprising each category are randomly chosen from the set listed in table $1 .{ }^{18}$ We then sum the utilities in each basket, and calculate the mean and covariance overall all observations. We then calculate the implied probability of each draw assuming the assumption that the utilities are drawn from the empirical multivariate distribution. ${ }^{19}$ With this approach, our basket utilities capture the interaction in utility from purchasing items in different categories, while not imposing the somewhat-artificial constraint that baskets are singular items.

A natural comparison to our multivariate approach is to consider the shopping-basket model of Wildenbeest (2011). Therefore, we compare the share-searching and cost-of-search estimates derived from our multivariate search model to those implied by the shoppingbasket model of Wildenbeest (2011). In order to facilitate a direct comparison between the two approaches, we use the same random-shopping baskets in each case, but estimate a univariate utility associated with the entire shopping basket in the Wildenbeest (2011) approach. While the contents of the basket are the same, the latter approach implicitly assumes that consumers search only for a basket of goods, and not each item that comprises the basket. As such, there is no need to consider the multivariate utility distribution, as

\footnotetext{
${ }^{17}$ If we had access to volume data, it would be theoretically possible to estimate a formal model of demand in which we accounted for all possible basket combinations, as in the multi-variate logit (MVL) model of Russell and Petersen (2000) or Kwak, Duvvuri, and Russell (2015), the multinomial probit model of Manchanda, Ansari, and Gupta (1999) or the discrete-continuous model of multi-category choice described in Smith and Thomassen (2012). However, as these authors note, the curse of dimensionality quickly overwhelms any attempt to construct truly representative shopping baskets.

${ }^{18}$ While this may not be perfectly descriptive of how online shoppers purchase, it is both reasonable and not likely to introduce bias into our basket-utility estimates. Alternatively, if we were to pair only the top brands from each category in one basket, and the lesser brands from each category in another, then we are likely to create an artificial source of positive correlation among brand-level utilities in each basket.

${ }^{19}$ Code that uses the EmpiricalDistribution script in Mathematica (version 10.3) is available from the authors.
} 
shoppers only compare the entire utility from a basket purchased at each store using the univariate search model outlined in section 4.1 above.

In each case, we use the equilibrium vector of utilities to calculate the share searching each number of stores $(1,2,3$, or 4 in our empirical application) and the implied costs of searching. By calculating equilibrium utilities, and search costs, with and without variety effects, we are able to assess the magnitude of the bias in estimated search cost when ignoring the effect of product variety on utility in multi-product retail environments. In the next section, we describe the results associated with each hedonic estimation model, and the equilibrium search costs in the univariate, and multivariate search cases.

\section{$5 \quad$ Results and Discussion}

In this section, we first present the results obtained from estimating the utility associated with each brand in each category, with and without variety effects, and then the estimated search behavior in our univariate and multivariate search cases. We interpret our results in terms of both the significance of search in our focal product categories, and the revealed cost of searching within each. We conclude the section with a number of robustness tests that establish the validity of our empirical model.

To estimate search costs while controlling for the possibility that online retailers are vertically differentiated, we follow Wildenbeest (2011) and estimate hedonic pricing models for each category. ${ }^{20}$ The results obtained by estimating the hedonic models appear in table 3. In this table, the item-specific terms represent the willingness to pay for each brand in the order listed in table 1, holding the store constant, while the store effects show the average difference in willingness to pay relative to store 4 (Waitrose). In the cereal category, for example, each cereal can be expected to sell for an average of nearly 15 pence more in Tesco relative to Waitrose, almost 30 pence less in Asda, and over 24 pence less in Sainsbury's.

\footnotetext{
${ }^{20}$ Wildenbeest (2011) explains that interpreting the maximum observed price as the willingness to pay, and calculating each valuation as the difference between willingness to pay and the observed price, is another alternative. We choose hedonic modeling as it allows us to easily estimate the effect of variety on productspecific valuations.
} 
Note that the store fixed-effect is not consistent in sign across categories. That is, soda sells for a discount relative to Waitrose in all 3 of the other stores, while jam sells at a premium to Waitrose in all the others. This is an important result as it shows that the perception of vertical differentiation cannot be assumed to be uniform across categories, so there is some feature of category-specific offerings that renders one store better than the others.

[table 3 in here]

The results in this table also include the marginal effect of variety on equilibrium prices in each category. In this table, the variety effects are predominantly, but not uniformly, positive. That is, the more variety in a category, the higher the willingness to pay for individual brands in each category and retailer. Although this finding is consistent with previous empirical results on variety effects on utility (Richards and Hamilton 2006), it is contrary to the evidence cited by Rhodes (2015). The fact that not all of the variety-effect estimates are positive underscores the controversy over the effect of product variety on multiproduct search costs. Namely, the choice overload hypothesis (Diehl and Poynor 2010) suggests that shoppers become overwhelmed when the number of choices is too large, and fail to make a purchase at all. ${ }^{21}$ Conversely, if greater variety implies that shoppers can find a brand that fits their ideal attribute combination more easily, the willingness to pay for individual brands in a store with more variety should be higher. In a reduced-form model such as this, we only see the net effect as either negative or positive. How these variety effects filter through to the cost of search, however, depends on the equilibrium impact on retailer pricing, and consumer search behavior.

These estimates are shown in table 4 below. In the first 3 estimated columns of table 4 , we show the share searching, the statistical significance of the share parameter, and the implied cost of search in the model without variety effects in utility, and in the latter 3 columns,

\footnotetext{
${ }^{21}$ We attempted to test the choice overload hypothesis directly by including quadratic variety terms in each equation. However, we encountered significant multicollinearity problems in each model. For example, a condition score of 30 indicates potential multicollinearity problems, at which point coefficient estimates may be unreliable, while our estimated condition score for the cereal model was 244,213 . Therefore, we may be able to include quadratic terms and obtain a better fit to the data, but given that each coefficient could not be trusted, the model could not be used to test the choice overload hypothesis.
} 
we show the same parameters with variety-effects included. Because we estimate the model using maximum likelihood, we evaluate goodness-of-fit using the likelihood-ratio index (LRI, McFadden 1973). Despite its parsimony, the model does a relatively good job in explaining the pattern of utility dispersion of the data as the average LRI value is well above $40 \% .^{22}$ Note in this table that we estimate only the first three share parameters as they are, logically, constrained to equal 1 in equilibrium. For the cereal category, we find that nearly $92 \%$ of shoppers consider only one store, while $7 \%$ shop two online stores, $1 \%$ shop three stores, and a negligible proportion shop all four stores. Meanwhile, the cost of search is substantial. Based on the average package prices reported in table 2, the cost of searching one store is fully $2.55 \%$ of the shelf price. While this is proportionately lower than the search costs reported by Brynjolffson and Smith (2000) and Hong and Shum (2006) for non-grocery products, it is higher than the corresponding values reported by Wildenbeest (2011) in a similar context. Measured the same way, the other categories exhibit considerable heterogeneity in search costs, ranging from only $0.01 \%$ of the shelf price in the yogurt category to nearly $105 \%$ for coffee. While the estimate for coffee seems high, it is nonetheless only slightly higher than the relative price differentials or search costs reported in Brynjolffson and Smith (2000, 33\%), Brynjolffson, Dick, and Smith (2010, 60\%), and Hong and Shum (2006, $128 \%$ in one case). One pattern seems clear from these estimates - products that are more frequently purchased tend to have lower search costs, which is both intuitive and to be expected.

[table 4 in here]

We examine how including variety as an argument of utility influences search cost estimates by comparing the estimates in the first three columns of table 4 to those in the final three columns. Notice for all product categories, restricting consumer utility to be unrelated to product variety results in systematic upward bias in the search cost estimates. For the

\footnotetext{
${ }^{22}$ By construction, the LRI is designed to be interpreted in a manner similar to the more usual coefficient of determination $\left(R^{2}\right)$ as it is bound by 0 and 1 , with values closer to 1 indicating that the estimated model provides a better fit to the data. The LRI statistic is calculated as $L R I=1-L L F / L L F_{0}$ where $L L F$ is the estimated log-likelihood function value, and $L L F_{0}$ is the log-likelihood function value under a null model, generally defined as one in which all parameters are restricted to zero but the constant. In this application, the "null" model is a naive model in which it is assumed consumers search all stores.
} 
cereal category, estimated search costs are 0.0538 pence in the model with variety effects in utility compared with 0.0633 pence per package in the model absent utility effects, and the estimated proportion of shoppers who consider only one store is higher - from $91 \%$ to almost 97\% - in the model that includes consumer preferences for variety. Similar results hold in all categories studied. Allowing for product variety effects in consumer utility functions thus appears to play an essential role in determining search costs and shopping frequency that has not been considered elsewhere in the literature.

Although the orthodox expectation is that online grocery shopping reduces search costs, and causes grocery markets to be more competitive, the outcome in the single-product search case is only partly consistent. Online retailers have the ability to offer far more variants of each brand than do bricks-and-mortar retailers, but this does not necessarily mean that markets will be more competitive; however, these conclusions are based only on a singleproduct analysis of search behavior.

Recall that predictions of how multiproduct and single-product search differ in terms of their implications for retail prices is unsettled in the theoretical literature. While Zhou (2012) and Rhodes (2015) argue that consumers will search more intensively in a multiproduct environment, so retail prices will be positively correlated, moving both upward and downward together, the earlier literature (Lal and Matutes 1994; McAfee 1995; Hosken and Reiffen 2007) instead finds that retailers use low prices on some searched items to attract consumers to the store, raising prices on other items. In terms of the cost of search, we find a similar result to the single-product search case above (table 5). Namely, the cost of searching through products in a single store fall by an amount comparable to the single productcase $(9.5 \%)$ when the variety effect is taken into account in a multi-product framework. However, search behavior differs dramatically, both with the multiproduct effect alone, and when the multiproduct search effect is combined with the variety effect. First, the results in table 5 show that consumers are more likely to search multiple stores when searching for products in many categories at the same time. This is perhaps to be expected as there is a 
chance the consumer will be unable to find his or her desired product in each category. In a single-product model, the probability of this one outcome alone drives the search to another store. In a multiproduct environment, however, if the consumer is unable to find the desired product in any of the five categories, she will likely try another store. As a result, fully $1.7 \%$ of consumers in the no-variety specification and over $5.1 \%$ in the variety specification are forced to search three of the four stores. More intensive search, in turn, suggests that retail prices across all categories are likely to be lower, supporting the "complementarity" argument of Rhodes (2015) and Zhou (2012).

[table 5 in here]

In order to assess the goodness-of-fit of the multiproduct model, we again use the LRI statistic for each model. Although Wildenbeest (2011) uses a Kolmogorov-Smirnov (KS) test to compare the empirical and estimated price and utility distributions for this purposes, the same approach is not available to us due because our utility distribution is multivariate, not univariate as assumed in the KS test. Therefore, as in the single-product case, we calculate LRI values for both the variety-inclusive and variety-exclusive models to measure goodness of fit. The results in table 5 show that the multiproduct search model provides a good fit to the data, resulting in a LRI statistic of 0.865 in the model absent variety effects and a LRI value of 0.948 in the model with variety effects in utility. While models with more covariates could likely do a better job in explaining the variation in utility from consuming each of these products, the merit of the empirical approach used here is its parsimony and its ability to capture complex price relationships with only a few parameters.

We next consider the variety effect in a model of multi-product search. The results in table 5 show that the complementarity outcome is sharpened when variation in variety is taken into account. Whereas the variety effect uniformly causes more consumers to search only one store in the single-product case, we see the opposite result when consumers search for products in all categories at once. Specifically, $90.1 \%$ of consumers search only one store without considering variety, while only $84.2 \%$ search one store when the variety effect is taken 
into account. More importantly, the fact that over twice the proportion of consumers search three of the four stores in the with-variety case compared to the no-variety case suggests that models that allow utility to vary with product variety result in substantially different search cost estimates.

Notice that suppressing variety effects in utility introduces bias in estimated search costs under multi-product search. To understand this result, recall the underlying structure of the search model: In equilibrium, consumers compare the marginal benefits of search to the marginal costs. In our empirical example, the cost of searching four stores relative to the cost of searching only one store averages $21.4 \%$ in the single-product / no-variety case, and $21.3 \%$ in the single-product / variety scenario. However, with search across multiple products, the ratio of four-store to one-store search costs changes from $20.0 \%$ without variety to $21.0 \%$ when variety is taken into account. Because the cost of search equals the benefits to search in equilibrium, the coefficient estimates suggest that there is greater benefit to searching all stores when consumer preferences for variety is taken into consideration. This finding is intuitive, because consumers are likely to consider multiple stores primarily because of the different assortments offered in each. For example, when searching for a specific flavor or package of jam in a basket that consists of the five categories considered here, a shopper is more likely to search across all four stores when the probability of finding a store that offers something specific and unique is higher in any of the product categories the retailer stocks.

This general finding is supported by estimates from a search model that treats multiple products as the choice of a single shopping basket, as in Wildenbeest (2011). Table 6 shows the results of this analysis. When consumers search only for a basket of goods, and do not search for multiple products as in our multivariate model, they are less willing to consider the same basket in another store (table 6), although the search cost-estimates are similar to those in Table 5. We interpret the primary difference among the two sets of results as suggesting that the shopping-basket model understates consumers' willingness to search among stores, because it does not capture the complementarity effect of multi-product 
purchasing decisions. Intuitively, when consumers shop for a single collection of goods, they are more likely to be able to find a comparable set of goods at another store, reducing the need to search. On the other hand, if consumers instead assemble a shopping basket as the result of 5 searches for separate items, they will be more willing to consider other stores when one of those searches cannot be completed to their satisfaction. Based on the LRI goodness-of-fit statistic, the shopping-basket model in table 6 also provides an inferior fit to the data relative to the multiproduct search model in table 5 . This is to be expected as the multiproduct model captures more information on consumers' search-and-buying behavior by including the covariance among item utilities. Ultimately, it is the relationship among items in the basket that drives the practical implications of our findings.

[table 6 in here]

There is a growing volume of research that predicts higher retail prices as online shopping becomes more prevalent. Bakos (1997), Anderson and Renault (1999), Degeratu, Rangaswamy, and Wu (2000), Cachon, Tierwiesch and Yu (2008), and Chu, Chintagunta, and Cebollada (2008) each argue for the potential rise in retail prices as consumers become less price sensitive - by whatever means - as they search for specific attribute mixes online. However, our results suggest the opposite. If consumers search for multiple products on the same "shopping trip," or online session with the intention of buying groceries, we find instead that the ability of retailers to offer deeper assortments online can indeed make these markets more competitive than previously thought by reducing incentives for consumer search.

There are other potential explanations for the pattern we observe. First, our findings may be a manifestation of the "long-tail" phenomenon in online retailing (Anderson 2006; Brynjolffson, $\mathrm{Hu}$, and Simester 2011). If search costs are indeed lower online, then the potential for retailers to offer nearly unlimited inventory means that tastes for otherwise "niche" products can now be met. As a result, the distribution of sales moves from a few high-selling products toward the long-tail of the distribution, and sales rise overall. However, while the retailers in our sample are able to offer large, and varying, assortments, it is far from 
clear that they approach the levels necessary to induce a long-tail effect. Second, our findings also may merely reflect the inherent complementarity in buying groceries by the basketful (Smith and Thomassen 2012). If consumers do not search at all, and instead buy all their groceries at one store in order to minimize fixed shopping-costs, then we may find a pattern of prices similar to that predicted by our model. Without access to purchase-quantities, however, we are not able to test our model directly against this alternative explanation. Further, there may be idiosyncrasies among UK food retailers that drive our results, such as differences inventory policies, unique cost shocks, or advertising that we simply do not observe. ${ }^{23}$ Because we model competition in utilities after accounting for retailer-specific effects, however, our approach accounts for these features as well as possible.

The primary implication of our findings is that online markets are likely to be considerably more competitive than single-product search models would leave us to believe. That said, we are unable to make a direct comparison between search online and offline, because our price-only data reflects only online transactions. Comparing our results for single- and multiproduct search suggests that the market power effects due to online search claimed in the literature may still hold true for retailers that sell items that are purchased infrequently and one at a time. Books, sporting equipment, electronic devices, or even shoes are prominent examples. Other retailers - supermarkets, drugstores, warehouse stores, for example - are designed to satisfy several needs at once. In these cases, the expansion of variety online is likely to represent a welfare gain to consumers, not just through the provision of more variety per se, but through the pro-competitive effects on online markets.

\section{Conclusion}

In this study, we investigate empirical estimates of consumer search costs, with and without variety effects, in an online environment, and in the context of an equilibrium, multiproduct model of search. With the rapid growth of online grocery retailing in a highly fragmented

\footnotetext{
${ }^{23}$ We thank an anonymous reviewer for pointing this out.
} 
offline industry, how the structure of retailing will impact consumer prices is an issue of growing importance for competition policy officials. While orthodox economic thought suggests that lower costs of searching online will reduce prices, online retailing allows virtually unlimited variety, and variety provision can enhance retail market power, raising retail prices and margins. Which of these two effects dominates in the multiproduct retail market equilibrium is the empirical question that motivates our research.

We estimate equilibrium price distributions with data from four major online supermarkets in the UK using maximum likelihood methods. We extend a well-understood empirical model of search costs to include variety-effects, and the effect of multiproduct search across five representative grocery categories. When restricting the model to a single-product search context, we find that considering consumer preferences for variety in utility functions reduces search cost estimates and increases the estimated likelihood that consumers shop in only one store. However, when we consider an equilibrium model of multi-product search, we find that models that consider consumer preferences for variety result in smaller search cost estimates, but a decrease in the estimated likelihood that consumers shop in only one store. Ignoring variety effects, therefore, result in substantial biases in estimated search costs.

On a substantive level, more intensive search has the potential to cause online grocery markets to be more competitive than markets for single-search goods such as books, electronics, or sporting goods, a finding that runs counter to much of the recent theoretical and empirical literature on the disruptive effects of online retailing in models that do not account for multiproduct interactions in consumer search.

Our findings are subject to the caveat that we consider only prices from a set of online retailers. A more comprehensive analysis of this issue would compare search costs, variety, and multiproduct retailing between online and offline retailers. Further, we consider products from only five typical grocery categories. Because supermarkets, whether online or offline, commonly stock products from hundreds of categories, we cannot rule out the possibility that a different set of products would produce different results. With a richer data set, 
we could also investigate whether the choice overload hypothesis is indeed an empirical regularity. We leave these questions for future validation of our results. Finally, our analysis is purely empirical. Multiproduct search models are notoriously complex, and often yield a multiplicity of equilibria (McAfee 1995). Future empirical research in this area would benefit from a more definitive theoretical background in order to test a more concrete set of hypotheses. 


\section{References}

[1] Anderson, S. P. and R. Renault. 1999. "Pricing, Product Diversity and Search Costs: A Bertrand-Chamberlin-Diamond Model." RAND Journal of Economics 30: 719-735.

[2] Anderson, C. 2006. The Long Tail: Why the Future of Business is Selling Less of More New York: Hyperion.

[3] Andrews, R. L., and I. S. Currim. 2004. "Behavioural Differences Between Consumers Attracted to Shopping Online versus Traditional Supermarkets: Implications for Enterprise Design and Marketing Strategy." International Journal of Internet Marketing and Advertising 1: 38-61.

[4] Armstrong, M., and J. Vickers. 2001. "Competitive Price Discrimination." RAND Journal of Economics 32: 579-605.

[5] Bakos, Y. 1997. "Reducing Buyer Search Cost: Implications for Electronic Marketplaces." Management Science 42: 1613-1630.

[6] Briesch, R. A., P. K. Chintagunta, and E. J. Fox. 2009. "How Does Assortment Affect Grocery Store Choice?" Journal of Marketing Research 46: 176-189.

[7] Bronnenberg, B. J., M. W. Kruger, and C. F. Mela. 2008. "Database Paper: The IRI Marketing Data Set." Marketing Science 27: 745-748.

[8] Brynjolfsson, E. and M. Smith. 2000. "Frictionless Commerce? A Comparison of Internet and Conventional Retailers." Management Science 46: 563-585.

[9] Brynjolfsson, E., A. A. Dick and M. D. Smith. 2010. "A Nearly Perfect Market? Differentiation vs. Price in Consumer Choice." Quantitative Marketing and Economics 8: $1-33$. 
[10] Brynjolfsson, E., Hu, Y., and D. Simester. 2011. "Goodbye Pareto Principle, Hello Long Tail: The Effect of Search Costs on the Concentration of Product Sales." Management Science 57: 1373-1386.

[11] Burdett, K. and Judd, K. 1983. "Equilibrium Price Dispersion." Econometrica 51: 955969.

[12] Butler, S. 2014. “Grocers Rush to Open 'Dark Stores' as Online Food Shopping Expands." The Guardian (http://www.theguardian.com /business/2014/jan/06). Accessed on April 3, 2014.

[13] Cachon, G. P., C. Terwiesch and X. Yu. 2008. "On the Effects of Consumer Search and Firm Entry in a Multiproduct Competitive Model." Marketing Science 27: 461-473.

[14] Carlson, J. A. and R. P. McAfee. 1983. "Discrete Equilibrium Price Dispersion." Journal of Political Economy 91: 480-493.

[15] Chen, P., and L. Hitt. 2003. "Understanding Price Dispersion in Internet-Enabled Markets." Working paper, Carnegie Mellon University, Pittsburgh.

[16] Chiappori, P. A., S. Levitt, and T. Groseclose. 2002. "Testing Mixed-strategy Equilibria when Players are Heterogeneous: The Case of Penalty Kicks in Soccer." American Economic Review 92: 1138-1151.

[17] Chu, J., P. Chintagunta, and J. Cebollada. 2008. "Research Note - A Comparison of Within-Household Price Sensitivity Across Online and Offline Channels." Marketing Science 27: 283-299.

[18] Clay, K., Krishnan, R., and Wolff, E. 2001. "Prices and Price Dispersion on the Web: Evidence from the Online Book Industry." Journal of Industrial Economics 49: 521-540. 
[19] Degeratu, A. M., A. Rangaswamy, and J. Wu. 2000. "Consumer Choice Behavior in Online and Traditional Supermarkets: The Effects of Brand Name, Price, and Other Search Attributes." International Journal of Research in Marketing 17: 55-78.

[20] De Los Santos, B., A. Hortacsu and M. R. Wildenbeest. 2012. "Testing Models of Consumer Search Using Data on Web Browsing and Purchasing Behavior." American Economic Review 102: 2955-2980.

[21] Hess, J. D., and E. Gerstner. 1987. "Loss Leader Pricing and Rain Check Policy." Marketing Science 6: 358-374.

[22] Hong, H. and M. Shum. 2006. "Using Price Distributions to Estimate Search Costs." RAND Journal of Economics 37: 257-275.

[23] Hosken, D., and D. Reiffen. 2007. "Pricing Behavior of Multiproduct Retailers." BE Journal of Theoretical Economics 7: 1-43.

[24] Jeuland, A. P. and C. Narasimhan. 1985. "Dealing - Temporary Price Cuts by Sellers as a Buyer Discrimination Mechanism." Journal of Business 58: 295-308.

[25] Lal, R., and C. Matutes. 1994. "Retail Pricing and Advertising Strategies." Journal of Business 67: 345-370.

[26] Kamakura, W., and K. Kwak. 2012. "Menu-choice Modeling." Working paper, Rice University, Department of Marketing.

[27] Kwak, K., S. D. Duvvuri, and G. J. Russell. 2015. "An Analysis of Assortment Choice in Grocery Retailing." Journal of Retailing 91: 19-33.

[28] Manchanda, P., A. Ansari, S. Gupta. 1999. "The Shopping Basket: A Model for Multicategory Purchase Incidence Decisions." Marketing Science 18: 95-114. 
[29] McFadden, D. 1973. "Conditional Logit Analysis of Qualitative Choice Behavior," in P. Zarembka (ed.), Frontiers in Econometrics. Academic Press: New York. pp. 105-142.

[30] McAfee, R. 1995. "Multiproduct Equilibrium Price Dispersion." Journal of Economic Theory 67: 83-105.

[31] McAlister, L., E. Pessemier. 1982. "Variety Seeking Behavior: An Interdisciplinary Review." Journal of Consumer Research 9: 311-322.

[32] Mehta, R., S. Rajiv and K. Srinivasan. 2003. "Price Uncertainty and Consumer Search: A Structural Model of Consideration Set Formation." Marketing Science 22: 58-84.

[33] Moraga-Gonzalez, J. L. and M. R. Wildenbeest. 2008. "Maximum Likelihood Estimation of Search Costs." European Economic Review 52: 820-848.

[34] Oppewal, H. and K. Koelemeijer 2005. "More Choice is Better: Effects of Assortment Size and Composition on Assortment Evaluation." International Journal of Research in Marketing 22: 45-60.

[35] Pesendorfer, M. 2002. "Retail Sales: A Study of Pricing Behavior in Supermarkets." Journal of Business 75: 33-66.

[36] Rhodes, A. 2015. "Multiproduct Retailing." forthcoming in the Review of Economic Studies.

[37] Richards, T. and S. Hamilton. 2006. "Rivalry in Price and Variety Among Supermarket Retailers." American Journal of Agricultural Economics 88: 710-726.

[38] Richards, T. and S. Hamilton. 2015. "Variety Pass-Through: An Examination of the Ready-to-Eat Cereal Market." Review of Economics and Statistics 97: 166-180.

[39] Richards, T., S. Hamilton, and J. Empen. 2015. "Attribute Search in Online Retailing." Cal Poly Working Paper No. 1504. 
[40] Russell, G. J. and A. Petersen. 2000. "Analysis of Cross Category Dependence in Market Basket Selection." Journal of Retailing 76: 367-92.

[41] Smith, H., O. Thomassen. 2012. "Multi-category Demand and Supermarket Pricing." International Journal of Industrial Organization 30: 309-314.

[42] Stahl, D. 1989. "Oligopolistic Pricing with Sequential Consumer Search." American Economic Review 79: 700-712.

[43] Trindade, A. 2010. "Price and Variety in Supermarkets: Can Store Competition Hurt Consumers?" Working paper, Department of Economics, Northwestern University.

[44] Varian, H. 1980. "A Model of Sales." American Economic Review 70: 651-659.

[45] Villas-Boas, J. M. 1995. "Models of Competitive Price Promotions: Some Empirical Evidence From the Coffee and Saltine Crackers Markets." Journal of Economics and Management Strategy 4: 85-107.

[46] Wang, Z. 2009. "(Mixed) Strategy in Oligopoly Pricing: Evidence from Gasoline Price Cycles Before and Under a Timing Regulation." Journal of Political Economy 117(6): 987-1030.

[47] Wilde, L. L., and A. Schwartz. 1979. "Equilibrium Comparison Shopping." Review of Economic Studies 46: 543-553.

[48] Wildenbeest, M. R. 2011. "An Empirical Model of Search with Vertically Differentiated Products." RAND Journal of Economics 42: 729-757.

[49] Zhou, J. 2012. "Multiproduct Search." Working Paper, Stern School of Business, New York University, New York, NY. 


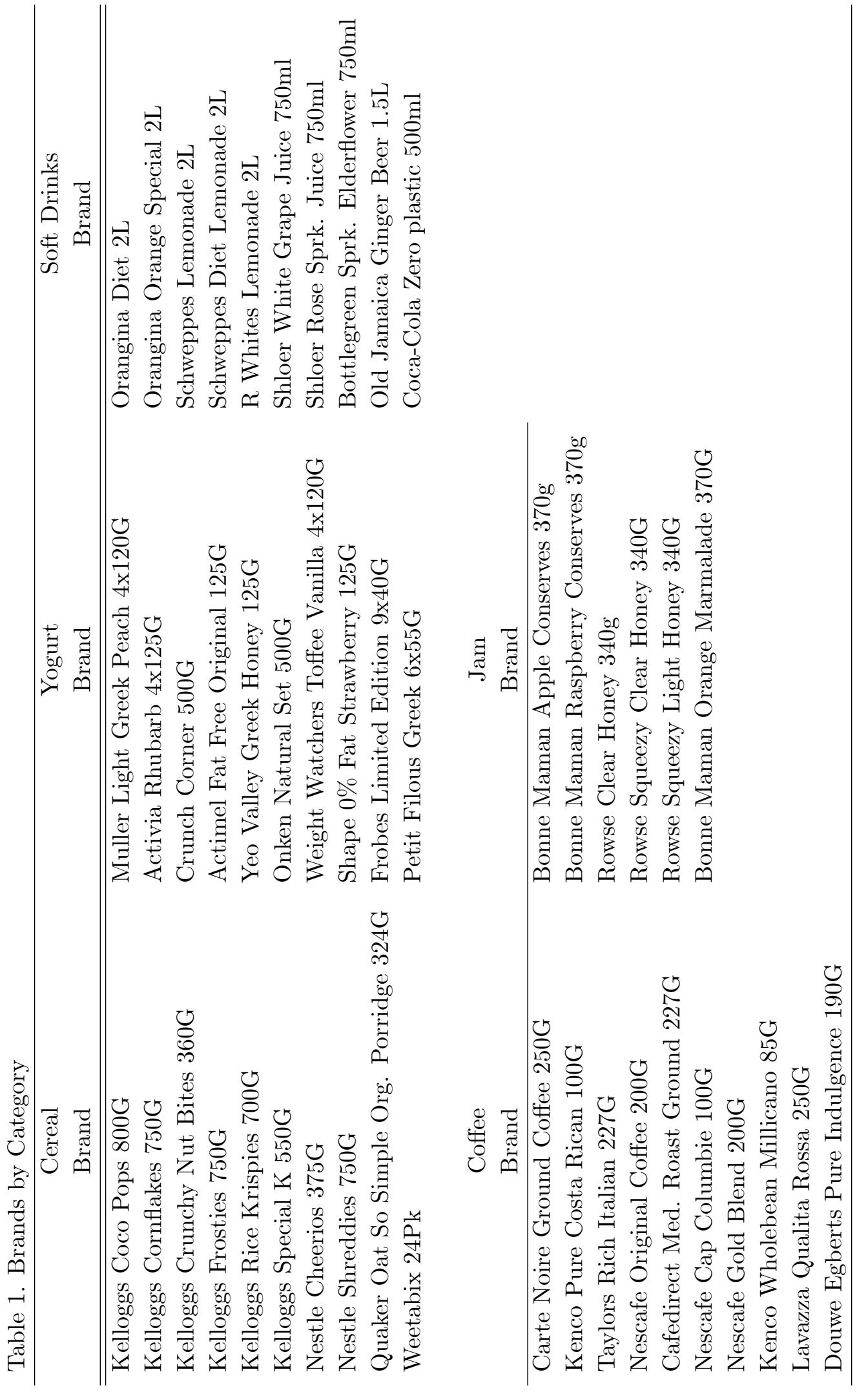


Table 2. Price and Variety Data by Item and Retailer

\begin{tabular}{lcccr}
\hline & \multicolumn{2}{c}{ Price } & \multicolumn{3}{c}{ Variety } \\
& Mean & Std. Dev. & Mean & Std. Dev. \\
\hline \hline Tesco & 2.4863 & 0.4836 & 272.4960 & 42.7965 \\
Asda & 2.3538 & 0.3974 & 420.8991 & 53.5006 \\
Sainsbury & 2.5117 & 0.3583 & 1624.2160 & 232.1755 \\
Waitrose & 2.5671 & 0.4172 & 443.0076 & 76.9898 \\
& \multicolumn{5}{c}{ Yogurt } \\
Tesco & 3.7633 & 0.5811 & 152.6127 & 20.4722 \\
Asda & 3.6179 & 0.6113 & 157.6098 & 8.4738 \\
Sainsbury & 3.7592 & 0.7108 & 998.1110 & 112.8924 \\
Waitrose & 3.8281 & 0.5581 & 409.9381 & 6.0211 \\
& \multicolumn{5}{c}{ Soda } \\
Tesco & 2.2119 & 0.2747 & 105.3842 & 26.5682 \\
Asda & 2.1278 & 0.3749 & 95.9499 & 8.0242 \\
Sainsbury & 2.1721 & 0.4006 & 337.0887 & 54.0515 \\
Waitrose & 2.3118 & 0.3061 & 266.4560 & 17.0483 \\
& \multicolumn{5}{c}{ Coffee } \\
Tesco & 1.4843 & 0.3410 & 344.1006 & 74.0740 \\
Asda & 1.4590 & 0.4258 & 174.7514 & 11.0206 \\
Sainsbury & 1.5429 & 0.3743 & 2011.2330 & 103.9917 \\
Waitrose & 1.5031 & 0.3948 & 400.1559 & 44.1049 \\
& \multicolumn{5}{c}{ Jam } \\
Tesco & 2.2176 & 0.8430 & 159.0717 & 22.4901 \\
Asda & 1.8483 & 0.5736 & 362.4859 & 44.1759 \\
Sainsbury & 2.1641 & 0.8492 & 1475.7510 & 276.9420 \\
Waitrose & 2.1493 & 0.7647 & 424.9373 & 24.1799 \\
\hline Note: Prices are calculated over EAN-matched items.
\end{tabular}




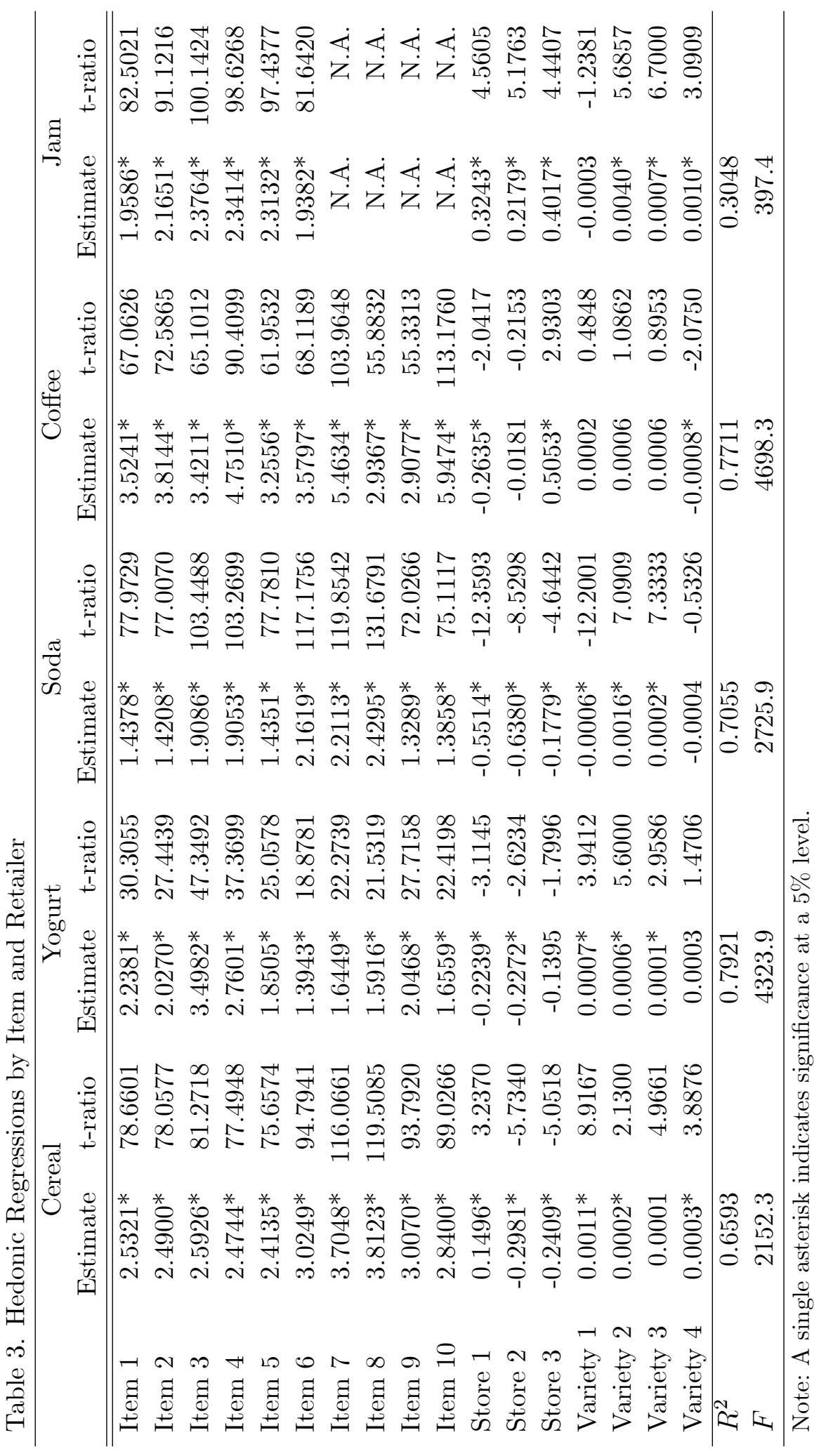


Table 4. Cost of Search with and without Variety Effects

\begin{tabular}{|c|c|c|c|c|c|c|c|}
\hline \multirow[b]{2}{*}{ Category } & \multirow[b]{2}{*}{ \# Stores } & \multicolumn{3}{|c|}{ Without Variety } & \multicolumn{3}{|c|}{ With Variety } \\
\hline & & $\begin{array}{c}\text { Share } \\
\text { Searching }\end{array}$ & t-ratio & $\begin{array}{l}\text { Cost of } \\
\text { Search }\end{array}$ & $\begin{array}{c}\text { Share } \\
\text { Searching }\end{array}$ & t-ratio & $\begin{array}{l}\text { Cost of } \\
\text { Search }\end{array}$ \\
\hline \multirow[t]{4}{*}{ Cereal } & 1 & 0.9167 & -1.6680 & 0.0633 & 0.9697* & $1,526.3625$ & 0.0538 \\
\hline & 2 & $0.0715^{*}$ & 4.1937 & 0.0318 & $0.0232^{*}$ & 12.9553 & 0.0274 \\
\hline & 3 & $0.0118^{*}$ & 4.8334 & 0.0191 & $0.0071^{*}$ & 5.4856 & 0.0166 \\
\hline & 4 & 0.0000 & & 0.0128 & 0.0000 & & 0.0111 \\
\hline $\mathrm{LLF} / \mathrm{LR}$ & & $-39,051.62$ & 0.7931 & & $-8,080.57$ & 0.7508 & \\
\hline \multirow[t]{4}{*}{ Yogurt } & 1 & $0.9112^{*}$ & 43.3471 & 0.0446 & $0.9708^{*}$ & 5.2547 & 0.0162 \\
\hline & 2 & $0.0640^{*}$ & 25.3243 & 0.0232 & $0.0222^{*}$ & 3.1651 & 0.0085 \\
\hline & 3 & $0.0183^{*}$ & 18.5652 & 0.0142 & $0.0070^{*}$ & 4.3549 & 0.0053 \\
\hline & 4 & 0.0065 & & 0.0097 & 0.0001 & & 0.0036 \\
\hline LLF / LR & & $-23,356.71$ & 0.2585 & & $-23,389.86$ & 0.0488 & \\
\hline \multirow[t]{4}{*}{ Soda } & 1 & $0.9392^{*}$ & 2.9140 & 0.5257 & 0.9698* & 2.3022 & 0.3353 \\
\hline & 2 & $0.0398^{*}$ & 79.9110 & 0.2788 & $0.0231^{*}$ & 2.1716 & 0.1761 \\
\hline & 3 & $0.0210^{*}$ & 182.9870 & 0.1733 & $0.0071^{*}$ & 7.0138 & 0.1090 \\
\hline & 4 & 0.0000 & & 0.1183 & 0.0000 & & 0.0742 \\
\hline LLF / LR & & $-43,883.21$ & 0.3838 & & $-22,905.15$ & 0.4701 & \\
\hline \multirow[t]{4}{*}{ Coffee } & 1 & $0.9147^{*}$ & 4.3737 & 1.5683 & 0.9501* & 4.4192 & 1.2480 \\
\hline & 2 & $0.0684^{*}$ & 4.3906 & 0.7976 & $0.0418^{*}$ & 4.5810 & 0.6390 \\
\hline & 3 & $0.0169^{*}$ & 4.1998 & 0.4833 & $0.0081^{*}$ & 3.6675 & 0.3892 \\
\hline & 4 & 0.0000 & & 0.3243 & 0.0000 & & 0.2622 \\
\hline LLF / LR & & $-59,070.84$ & 0.2205 & & $-41,609.79$ & 0.3699 & \\
\hline \multirow[t]{4}{*}{ Jam } & 1 & 0.9199* & 2.0291 & 0.4771 & 0.9661 & 0.9902 & 0.4507 \\
\hline & 2 & $0.0429^{*}$ & 2.7118 & 0.2565 & 0.0266 & 1.0835 & 0.2353 \\
\hline & 3 & 0.0372 & 1.2485 & 0.1604 & $0.0073^{*}$ & 7.2928 & 0.1450 \\
\hline & 4 & 0.0000 & & 0.1098 & 0.0000 & & 0.0985 \\
\hline LLF / LR & & $-59,066.28$ & 0.2139 & & $-14,817.88$ & 0.4398 & \\
\hline
\end{tabular}

Note: A single asterisk indicates significance at a $5 \%$ level. LR is the likelihood ratio index.

Table 5. Cost of Search with and without Variety in Multiproduct Retailing

\begin{tabular}{lrrrrrr}
\hline & \multicolumn{2}{c}{ Without Variety } & \multicolumn{3}{c}{ With Variety } \\
\# Stores & $\begin{array}{c}\text { Share } \\
\text { Searching }\end{array}$ & \multicolumn{1}{c}{ t-ratio } & $\begin{array}{c}\text { Cost of } \\
\text { Search }\end{array}$ & $\begin{array}{c}\text { Share } \\
\text { Searching }\end{array}$ & t-ratio & $\begin{array}{c}\text { Cost of } \\
\text { Search }\end{array}$ \\
\hline \hline 1 & $0.9079^{*}$ & $19,066.7500$ & 1.7779 & $0.8420^{*}$ & $4,080.6341$ & 1.6082 \\
2 & $0.0732^{*}$ & $1,288.5888$ & 0.8915 & $0.1045^{*}$ & 391.0282 & 0.8022 \\
3 & $0.0173^{*}$ & 750.9889 & 0.5340 & $0.0515^{*}$ & 164.9541 & 0.4792 \\
4 & 0.0016 & & 0.3550 & 0.0020 & & 0.3380 \\
LLF/LRI & $-3,676.0600$ & 0.8651 & & $-1,370.3890$ & 0.9482 & \\
\hline
\end{tabular}

Note: A single asterisk indicates significance at a $5 \%$ level. 
Table 6. Cost of Search with and without Variety in Basket Model

\begin{tabular}{rrrrrrr}
\hline & \multicolumn{3}{c}{ Without Variety } & \multicolumn{3}{c}{ With Variety } \\
\# Stores & $\begin{array}{c}\text { Share } \\
\text { Searching }\end{array}$ & \multicolumn{1}{c}{ t-ratio } & $\begin{array}{c}\text { Cost of } \\
\text { Search }\end{array}$ & $\begin{array}{c}\text { Share } \\
\text { Searching }\end{array}$ & t-ratio & $\begin{array}{c}\text { Cost of } \\
\text { Search }\end{array}$ \\
\hline \hline 1 & $0.8327^{*}$ & 232.2821 & 1.8008 & $0.8204^{*}$ & $5,841.5103$ & 1.6255 \\
2 & $0.0196^{*}$ & 9.0516 & 1.0893 & $0.0231^{*}$ & 9.0516 & 0.9749 \\
3 & $0.0071^{*}$ & 2.3911 & 0.7242 & $0.0097^{*}$ & 2.3911 & 0.6444 \\
4 & 0.1407 & & 0.5133 & 0.1469 & & 0.4548 \\
LLF/LRI & -2.1031 & 0.3038 & & -1.9679 & 0.3526 & \\
\hline
\end{tabular}

Note: A single asterisk indicates significance at a $5 \%$ level. 